\title{
Impact of Organizational Justice (Distributive Justice, Procedural Justice, and Interactional Justice) on Job Satisfaction
}

\author{
Rashed Alneyadi, Mohammed Nusari, Ali Ameen, Amiya Bhaumik
}

\begin{abstract}
Perceptions of organizational justice constitute an important heuristic in organizational decision-making, as research relates it to job satisfaction, turnover, leadership, organizational citizenship, organizational commitment, trust, customer satisfaction, job performance, employee theft, role breadth, alienation, and leader-member exchange. The public sector in UAE is the focus of this paper. Applying the concept of organizational justice (distributive justice, procedural justice, interactional justice) to examine the effect of it on employees' satisfaction. The data was collected from 452 officers from 7 sectors in the ministry of interior in $U A E$ and analysed using structural equation modelling via SmartPLS 3.0. There were three main results: first, distributive justice has a positive impact on job satisfaction; second, procedural justice is significantly predicting job satisfaction; third, interactional justice has a significant impact on job satisfaction. The proposed model explained $33.7 \%$ of the variance in job satisfaction. Theoretical and practical implications are also provided.
\end{abstract}

Keywords: Organizational justice; distributive justice; procedural justice; interactional justice; job satisfaction.

\section{INTRODUCTION}

The effects of globalization, and competition on an international level, have rendered the recruitment, maintenance, and organization of resources, decisive factors for success in the public sector domain. In the services sector, it is acknowledged that the management of human resources, in particular, is a crucial factor. This is attributed to the fact that the services offered, and the supplier of these services, are, to a large extent, interconnected. In this regard, enhancing an employee's job satisfaction, dedication to the organization and motivation, will serve to promote his/her extra-role behaviour, by way of organizational citizenship behaviour. This, in turn, will contribute towards an improved standing of the public sector organization concerned, in terms of competitiveness. The close relationship between job satisfaction, and performance, is particularly evident in the service industry.

Revised Manuscript Received on September 25, 2019

Rashed ALNEYADI, Faculty of Business and Accountancy, Lincoln University College, Selangor, Malaysia

Mohammed NUSARI, Faculty of Business and Accountancy, Lincoln University College, Selangor, Malaysia

Ali Ameen, Faculty of Business and Accountancy, Lincoln University College, Selangor, Malaysia

Amiya Bhaumik, Faculty of Business and Accountancy, Lincoln University College, Selangor, Malaysia
In the field of organizational research, justice perceptions are viewed as explanatory variables. Organizational justice defines the perspective of individuals (or groups), with regards to the impartiality of an organization's conduct towards them, and the behavioural response of these individuals (or groups) towards this perspective. The extant literature classifies the three aspects of justice perceptions as distributive justice, procedural justice and interactional justice.

It has been established that perceived organizational justice is a significant antecedent to organizational citizenship behaviour. While the impact of justice perceptions on work attitude and work behaviour is well-documented in western literature, the same cannot be said for the situation in the United Arab Emirates (UAE). Here, studies focusing on this subject matter have, unfortunately, been rather few and far between.

\section{Literature REVIEW}

\section{A. Job Satisfaction (JS)}

Job satisfaction has to do with the attitudes or opinions of employees regarding their work specifically or their work setting as a whole, and their general sentiment as regards to their job requirements. The origins of the job satisfaction concept can be traced to an investigation conducted in the 1920s, which came to be known as the Hawthorne studies. The outcomes from this endeavour revealed that the emotions of a worker, has a significant effect on his/her behaviour at work. The job satisfaction and productivity levels of an employee are determined principally by his/her social and psychological circumstances.

Job satisfaction refers to an individual's response to his/her working situation. This response arises from a comparison between the real situation, and the situation that is anticipated, craved and required. Personal in nature, this response is indicative of the degree of contentment an employee experiences with regards to his/her job.

\section{B. Organizational Justice (OJ)}

Distributive justice has its roots in the equity theory. This theory focuses on the perception of a worker concerning his/her treatment, in comparison to other workers. The equity theory asserts that the contributions of employees towards the organization come in the form of education, effort and experience, among others.

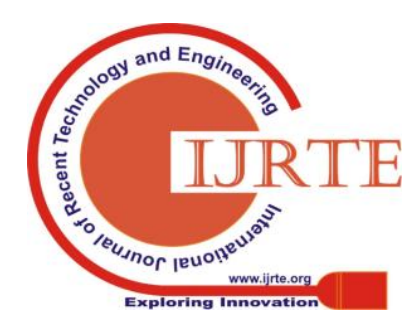


In view of these contributions, employees are entitled to returns in the way of salaries and promotions. The perceived ratio of what an employee receives as a result of his/her work, in comparison to the degree of effort put into the said work, serves to ascertain whether the situation is one of equity, or inequity. Put plainly, workers anticipate a response from the management that commensurate with their level of contribution in terms of work.

Procedural justice represents another route towards the assessment of impartiality with regards to decisions concerning remunerations, or decisions related to administrative issues. This concept contemplates the approach employed to arrive at these decisions. Procedural justice emphasizes on the perceived fairness, of the course adopted to decide on the severity of the penalty, or the scale of the remuneration doled out. Thus, the approach adopted to realize the results, may turn out to be of more significance, than the results themselves.

Interactional justice defines the degree of perceived fairness regarding the manner in which an employee is cared for by the establishment. Unlike procedural justice, the interaction occurring in interactional justice is of a more informal nature. It has to do with the level of integrity, compassion and respect displayed by management, during communications with employees. Procedural justice differs from interactional justice in that with the latter, the emphasis is on perceived justice, or injustice.

Several investigations have delved into the connection between the abovementioned modes of organizational justice, and their impact on work issues such as turnover intention, organizational commitment, organizational citizenship behaviour and job satisfaction. This led to proposal of the hypotheses as below:

H1. Distributive justice significantly has a positive impact on job satisfaction.

$\mathrm{H} 2$. Procedural justice significantly has a positive impact on job satisfaction.

H3. Interactional justice significantly has a positive impact on job satisfaction.

Figure 1 shows the proposed study model which was derived from the social exchange theory and contains three independent variables (distributive justice, procedural justice, and interactional justice) and one dependent variable (job satisfaction).

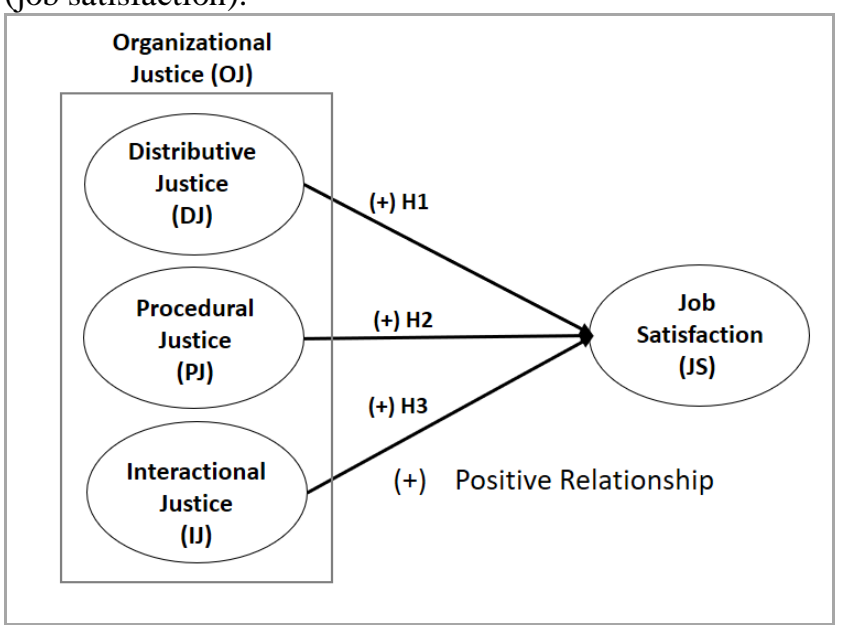

Fig. 1 The proposed model

Table 1: Measurement assessment results

\section{ReSEARCh DeSign AND Methodology}

\section{A. Instrument Development}

Equipped with information available in relevant literature, we applied a multi-item Likert scale for a 23-item questionnaire. As recommended in previous investigations, the constructs were gauged with the use of a 5-point Likert scale [1-3], with 5 signifying 'Strongly Agree' and 1 signifying 'Strongly Disagree'. Taking into consideration the fully Arab-speaking composition of respondents, the items in the questionnaire were accurately translated from English to Arabic. Back translation, a procedure frequently applied in cross-cultural surveys, was employed for this purpose. We referred to previous studies for the gauging of the variables (Appendix A).

\section{B. Data Collection}

Between April, 2018 and August, 2018, 600 self-administered questionnaires were handed out to government workers. Of these, 480 were returned, and 452 were considered for our survey. This sample size is similar to that used by Krejcie \& Morgan (1970) [4] for their study in this area. Our realized response rate of $60.42 \%$ can be deemed excellent, when compared to those of previous investigations, documented in relevant literature. Of the 28 removed questionnaires, 21 were found to have omitted answers to more than $15 \%$ of the questions, three were outliers, and 4 came with a straight lining.

\section{Data Analysis and Results}

The SmartPLS 3.0 software was used to examine our model through partial least squares (PLS) variance-based structural equation modelling (VB-SEM). A two-stage analytical procedure was utilized for (a) evaluating the measurement model (validity and reliability), and (b) evaluating the structural model (hypothesized relationships analysis).

\section{A.Descriptive analysis}

Job satisfaction score the highest with mean 3.356 out of 5.0, with a standard deviation of 1.148. Distributive justice score the lowest with mean 2.991 out of 5.0, with a standard deviation of 0.944 , as Table 1 shows.

\section{B.Measurement Model Assessment}

The measurement model was assessed for construct reliability and validity. The values of every single Cronbach's alpha surpassed the targeted value of 0.7 [5]. Additionally, the test for construct reliability revealed that every composite reliability (CR) value, also went beyond 0.7 [6]. Factor loadings were used to evaluate indicator reliability. Except for IJ5 and IJ6, the values recorded exceeded the sought after value of 0.7. IJ5 and IJ6 were subsequently discarded from the scale, due to depleted loading values. Convergent validity was evaluated by way of average variance extracted (AVE). The values attained topped the objective value of 0.50 . These evaluation results are exhibited in Table 1. 
International Journal of Recent Technology and Engineering (IJRTE) ISSN: 2277-3878, Volume-8 Issue-2S10, September 2019

\begin{tabular}{|c|c|c|c|c|c|c|c|}
\hline Constructs & Item & $\begin{array}{c}\text { Loading } \\
(>0.5)\end{array}$ & M & SD & $\begin{array}{c}\alpha \\
(>0.7)\end{array}$ & $\begin{array}{c}\mathrm{CR} \\
(>0.7)\end{array}$ & $\begin{array}{c}\text { AVE } \\
(>0.5)\end{array}$ \\
\hline \multirow{5}{*}{$\begin{array}{l}\text { Distributive } \\
\text { Justice } \\
\text { (DJ) }\end{array}$} & DJ1 & 0.791 & \multirow{5}{*}{2.991} & \multirow{5}{*}{0.944} & \multirow{5}{*}{0.919} & \multirow{5}{*}{0.939} & \multirow{5}{*}{0.756} \\
\hline & $\mathrm{DJ} 2$ & 0.877 & & & & & \\
\hline & DJ3 & 0.894 & & & & & \\
\hline & DJ4 & 0.904 & & & & & \\
\hline & DJ5 & 0.877 & & & & & \\
\hline \multirow{6}{*}{$\begin{array}{l}\text { Procedural } \\
\text { Justice } \\
(\mathrm{PJ})\end{array}$} & PJ1 & 0.916 & \multirow{6}{*}{3.131} & \multirow{6}{*}{1.043} & \multirow{6}{*}{0.940} & \multirow{6}{*}{0.953} & \multirow{6}{*}{0.771} \\
\hline & $\mathrm{PJ} 2$ & 0.837 & & & & & \\
\hline & $\mathrm{PJ} 3$ & 0.908 & & & & & \\
\hline & PJ4 & 0.889 & & & & & \\
\hline & PJ5 & 0.829 & & & & & \\
\hline & PJ6 & 0.885 & & & & & \\
\hline \multirow{9}{*}{$\begin{array}{l}\text { Interactional } \\
\text { Justice } \\
\text { (IJ) }\end{array}$} & IJ1 & 0.853 & \multirow{9}{*}{2.997} & \multirow{9}{*}{0.729} & \multirow{9}{*}{0.900} & \multirow{9}{*}{0.921} & \multirow{9}{*}{0.626} \\
\hline & $\mathrm{IJ} 2$ & 0.789 & & & & & \\
\hline & IJ3 & 0.833 & & & & & \\
\hline & IJ4 & 0.786 & & & & & \\
\hline & IJ5 & Deleted & & & & & \\
\hline & IJ6 & Deleted & & & & & \\
\hline & IJ7 & 0.844 & & & & & \\
\hline & IJ8 & 0.713 & & & & & \\
\hline & IJ9 & 0.709 & & & & & \\
\hline Job & JS1 & 0.934 & \multirow{3}{*}{3.356} & \multirow{3}{*}{1.148} & \multirow{3}{*}{0.921} & \multirow{3}{*}{0.950} & \multirow{3}{*}{0.864} \\
\hline \multirow{2}{*}{$\begin{array}{c}\text { Satisfaction } \\
(\mathrm{JS})\end{array}$} & JS2 & 0.927 & & & & & \\
\hline & JS3 & 0.927 & & & & & \\
\hline
\end{tabular}

Note: $\mathrm{M}=$ Mean; $\mathrm{SD}=$ Standard Deviation, $\alpha=$ Cronbach's alpha; $\mathrm{CR}=$ Composite Reliability, AVE = Average Variance Extracted.

Key: DJ: Distributive Justice, PJ: Procedural Justice, IJ: Interactional Justice, JS: Job Satisfaction

The discriminant validity of the measurement model was assessed through cross-loadings and the Fornell-Larcker criterion. Cross-loadings are typically the initial step for tests on the discriminant validity of indicators. The requirements for discriminant validity in our model were considered met, as the indicators' outer loadings on a construct, surpassed its cross-loadings with other constructs. The evaluation results for discriminant validity through cross-loadings are displayed in Table 2.

Table 2: Results of discriminant validity by the cross loading

\begin{tabular}{|c|c|c|c|c|}
\hline & $D J$ & $P J$ & $I J$ & $J S$ \\
\hline DJ1 & 0.791 & 0.503 & 0.417 & 0.357 \\
\hline DJ2 & 0.877 & 0.596 & 0.515 & 0.416 \\
\hline DJ3 & 0.894 & 0.618 & 0.530 & 0.437 \\
\hline DJ4 & 0.904 & 0.640 & 0.609 & 0.500 \\
\hline DJ5 & 0.877 & 0.612 & 0.515 & 0.418 \\
\hline PJ1 & 0.635 & 0.916 & 0.576 & 0.494 \\
\hline $\mathrm{PJ} 2$ & 0.549 & 0.837 & 0.499 & 0.389 \\
\hline PJ3 & 0.612 & 0.908 & 0.569 & 0.503 \\
\hline PJ4 & 0.638 & 0.889 & 0.566 & 0.469 \\
\hline PJ5 & 0.532 & 0.829 & 0.522 & 0.412 \\
\hline PJ6 & 0.637 & 0.885 & 0.553 & 0.471 \\
\hline IJ1 & 0.477 & 0.485 & 0.853 & 0.398 \\
\hline $\mathrm{IJ} 2$ & 0.401 & 0.403 & 0.789 & 0.344 \\
\hline IJ3 & 0.435 & 0.443 & 0.833 & 0.365 \\
\hline IJ4 & 0.407 & 0.414 & 0.786 & 0.352 \\
\hline IJ7 & 0.488 & 0.503 & 0.844 & 0.411 \\
\hline IJ8 & 0.509 & 0.566 & 0.713 & 0.404 \\
\hline IJ9 & 0.561 & 0.592 & 0.709 & 0.450 \\
\hline JS1 & 0.457 & 0.483 & 0.453 & 0.934 \\
\hline
\end{tabular}


Impact of Organizational Justice (Distributive Justice, Procedural Justice, and Interactional Justice) on Job Satisfaction

\begin{tabular}{c|cccc}
\hline JS2 & 0.473 & 0.483 & 0.463 & $\mathbf{0 . 9 2 7}$ \\
JS3 & 0.446 & 0.492 & 0.473 & $\mathbf{0 . 9 2 7}$ \\
\hline
\end{tabular}

Key: DJ: Distributive Justice, PJ: Procedural Justice, IJ: Interactional Justice, JS: Job Satisfaction

Table 3 shows the results for discriminant validity acquired through the Fornell-Larcker criterion. As can be gathered from this table, the square root of the AVEs on the diagonals (portrayed in bold) are higher than the correlations between constructs (matching row and column values). This indicates a clearer linkage between the constructs and their individual indicators, as compared to the other constructs in the model. A similar outcome was seen in which it was indicative of superior discriminant validity. The correlation of the exogenous constructs in our study was observed to be below 0.85 (Awang, 2014). In view of the above, the discriminant validity for all the constructs in our investigation can be deemed adequately met.

Table 3: Results of discriminant validity by Fornell-Larcker criterion

\begin{tabular}{c|cccc}
\hline & $D J$ & $I J$ & $J S$ & $P J$ \\
\hline DJ & $\mathbf{0 . 8 6 9}$ & & & \\
IJ & 0.601 & $\mathbf{0 . 7 9 1}$ & $\mathbf{0 . 9 3 0}$ & 0.523 \\
JS & 0.493 & 0.498 & 0.625 & $\mathbf{0 . 8 7 8}$ \\
PJ & 0.686 & 0.525 \\
\hline
\end{tabular}

Note: Diagonals represent the square root of the average variance extracted while the other entries represent the correlation s.

Key: DJ: Distributive Justice, PJ: Procedural Justice, IJ: Interactional Justice, JS: Job Satisfaction

\section{Structural Model Assessment}

procedure with a resample of 5,000.

The structural model can be tested by computing beta $(\beta)$,

$\mathrm{R}^{2}$, and the corresponding t-values via a bootstrapping

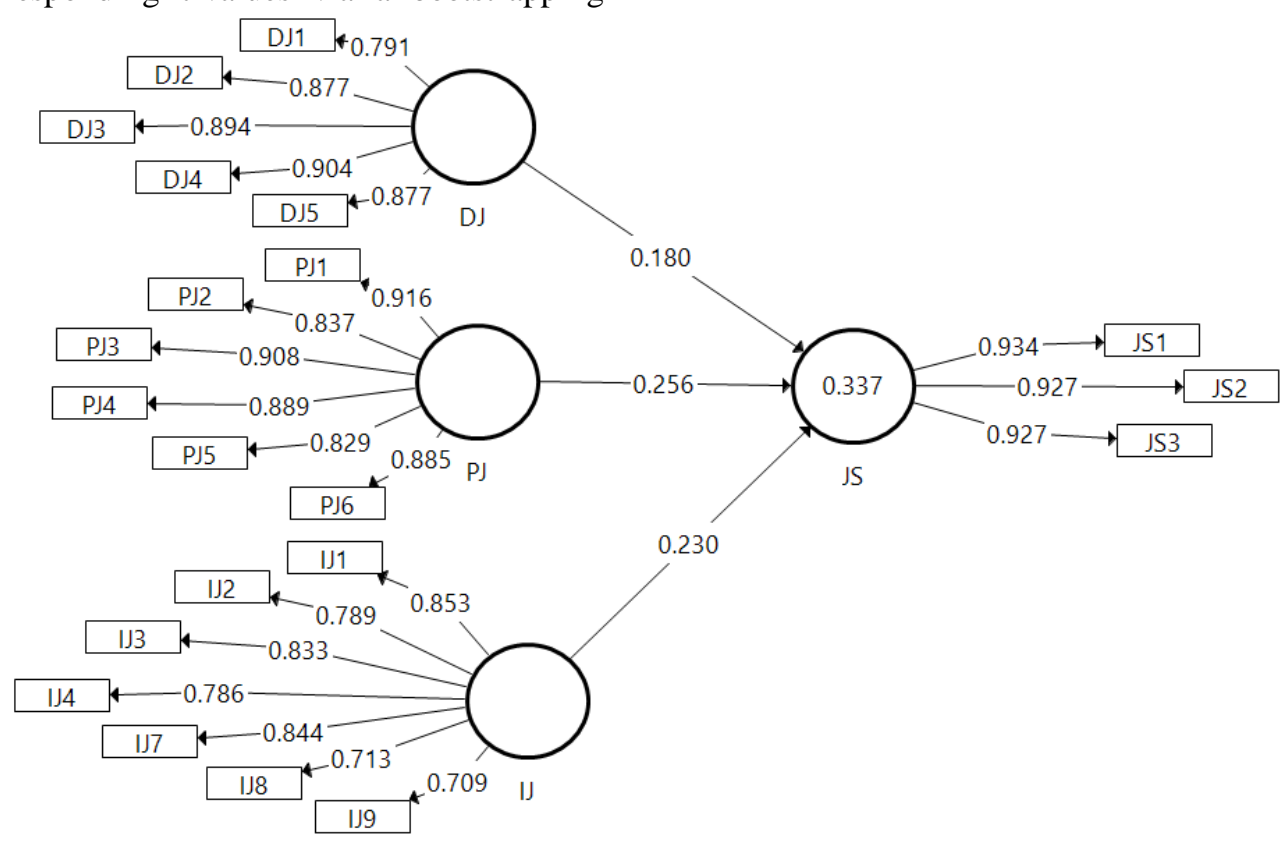

Key: DJ: Distributive Justice, PJ: Procedural Justice, IJ: Interactional Justice, JS: Job Satisfaction

Fig 2: PLS algorithm results

Figure 2 and Table 4 depict the structural model assessment, showing the results of the hypothesis tests, with 3 out of the 3 hypotheses are supported. Distributive justice, procedural justice, and interactional justice significantly predict job satisfaction. Hence, $\mathrm{H} 1, \mathrm{H} 2$, and $\mathrm{H} 3$ are accepted with $\quad(\beta=0.180, \mathrm{t}=2.825, \mathrm{p} \quad<0.01)$, $(\beta=0.256, \mathrm{t}=3.909, \mathrm{p} \quad<0.001)$, $(\beta=0.230, \mathrm{t}=3.500, \mathrm{p}<0.001)$ respectively.
The strength of the relationship between exogenous and endogenous constructs are measured by the standardised path coefficients, which in this case show that the direct effects of procedural justice on job satisfaction is much stronger than the influence of other variables.

Thirty-four percent of the variance in job satisfaction is explained by distributive justice, procedural justice, and interactional justice. The values of $\mathrm{R}^{2}$ have an acceptable level of explanatory power, indicating a substantial model. 
Table 4: Structural assessment results

\begin{tabular}{cllllllc}
\hline \hline Hypothesis & Relationship & Std Beta & Std Error & t-value & p-value & Decision & $\mathrm{R}^{2}$ \\
\hline $\mathrm{H} 1$ & $\mathrm{DJ} \rightarrow \mathrm{JS}$ & 0.180 & 0.064 & 2.825 & 0.002 & Supported \\
$\mathrm{H} 2$ & $\mathrm{PJ} \rightarrow \mathrm{JS}$ & 0.256 & 0.065 & 3.909 & 0.000 & Supported \\
$\mathrm{H} 3$ & $\mathrm{IJ} \rightarrow \mathrm{JS}$ & 0.230 & 0.066 & 3.500 & 0.000 & Supported \\
\hline \hline
\end{tabular}

Key: DJ: Distributive Justice, PJ: Procedural Justice, IJ: Interactional Justice, JS: Job Satisfaction

\section{DISCUSSION}

Based on the proposed model, this study improves the understanding of the role played by organizational justice in terms of distributive justice, procedural justice, and interactional justice in predicting job satisfaction among employees in government sector in UAE, and highlights relevant implications. The discussions are further detailed in the following.

The study found that distributive justice positively affects job satisfaction among employees in government sector in UAE, this is supported by previous studies [7]. It is explained by the fact that the more the employee receive fair rewards with regard to responsibilities, education level, efforts, stress and the tension created by the job, and with regard to the fulfilled responsibilities. The more the employees are satisfied with the job and with the work he/she is doing.

Furtherm the results revealed that procedural justice has a significant influence on job satisfaction among employees in government sector in UAE which is also supported by previous studies [8]. It is explained by the fact that the more the supervisors are neutral about decision making, listening to others before decision making, gather the right information related to the topic of decision making, give additional information when necessary, have their decisions implemented to everyone consistently, and they have the right to deny or accept the decision. The more the employees is satisfied with the job and with the work he/she is doing.

Lastly, it was also found that interactional justice significantly predicts job satisfaction among employees in government sector in UAE, this is supported by previous studies. It is explained by the fact that the more the supervisors are polite and concerned for decisions about employee's job, respectful and careful about decisions about employee's job, sensitive to personal needs, give importance to personal rights, inform the employee about the implications of the decisions, have Logical explanations for decisions. The more the employees is satisfied with the job and with the work he/she is doing.

\section{IMPLICATIONS, LIMITATIONS AND FUTURE DIRECTIONS}

The results highlighted that organizational justice a strong impact on its employees' overall job satisfaction because the organizational justice provides a fair treatment of the employees. Given that each individual highly receives the organizational justice they will be ensured that they will take his/her right in the salary, career development, compensation, job security, respect, and appreciation. As all the organization's resources have been distributed fairly as well as these resourced must be distributed based on proper and fair procedures and the interactional justice - including respect and appreciation - is essential to be achieved, admittedly, their employees are highly likely to develop great job satisfaction.

Given that the employees' job satisfaction is greatly associated with the organizational justice, the top management in the organization has to measure the employees' perceptions of the organizational justice. The managers can evaluate these perceptions by using the current study's questionnaire. If the managers find the employees' feelings of the organizational justice are low, however, they developed high-quality distributive justice, procedural justice, and interactional justice. They should find the reasons of low perceptions of the organizational justice, perhaps the implications of these practices are not achieved properly.

Despite its strengths, this study has a limitation that also suggest areas for future research. This study was limited by police officers of the interior ministry in UAE. In the future research, the researcher suggests to investigate the study hypotheses in other geographical areas, as well as, the sample should include public and private sector to increase the generalization.

\section{Conclusion}

By way of conclusion, the main objective of this study was to deepen our understanding of the relationship between distributive justice, procedural justice and interactional justice, and job satisfaction. The perspectives of social exchange theory were applied to further develop our understanding of the link between the study variables. It has provided evidence from leading scholars in the field on the notion of 'organizational justice' and how it is essential to build the employees satisfaction. Regardless of various constraints to the study, the results have been encouraging, as it has managed to throw some lights on organizational justice in the public sector in the UAE. The results revealed that the three hypotheses are significant. The independent variables significantly explain $33.7 \%$ of job satisfaction. The implications of this study have been deliberated, some directions for future research have been suggested. 
Impact of Organizational Justice (Distributive Justice, Procedural Justice, and Interactional Justice) on Job Satisfaction

\author{
APPENDIX \\ Appendix A \\ Instrument for varibles \\ Varible \\ Measure \\ Source \\ DJ1: I receive fair rewards with regard to responsibilities in my organization. \\ DJ2: I receive fair rewards with regard to education level in my organization. \\ Distributive DJ3: I receive fair rewards with regard to the efforts in my organization \\ Justice DJ4: I receive fair rewards with regard to stress and the tension created by the \\ (DJ) job. \\ DJ5: I receive fair rewards with regard to the fulfilled responsibilities in my \\ organization. \\ PJ1: My supervisor is neutral about decision making. \\ PJ2: My supervisor is listening to others before decision making. \\ Procedural PJ3: My supervisor is collecting the right information related to the topic of \\ Justice decision making. \\ (PJ) PJ4: My supervisor is giving additional information when necessary \\ PJ5: My supervisor's decisions are implemented to everyone consistently. \\ PJ6: My supervisor has the right to deny or accept the decision. \\ IJ1: My supervisor is polite and concerned for decisions about my job. \\ IJ2: My supervisor is respectful and careful about decisions about my job. \\ IJ3: My supervisor is sensitive to personal needs for decisions about my job. \\ IJ4: My supervisor is sincere for decisions about my job. \\ Interactional \\ IJ5: My supervisor gives importance to personal rights for decisions about \\ Justice my job. \\ (IJ) \\ IJ6: My supervisor's implications of the decisions about my job is told to me. \\ IJ7: My supervisor's explanation for the decisions related to my job. \\ IJ8: My supervisor has Logic explanations for decisions taken about my job. \\ IJ9: My supervisor has a clear explanation for decisions related to my job. \\ Job JS1: All things considered, I am satisfied with my job. \\ Satisfaction JS2: I like my job. \\ (JS) \\ JS3: I am generally satisfied with the work I do in this job.

\section{REFERENCES} \\ 1. O. Isaac, Z. Abdullah, T. Ramayah \& M. Mutahar Ahmed, (2017). \\ 10. Palaiologos, Anastasios \& Papazekos, Panagiotis \& Panayotopoulou, \\ Leda. (2011). Organizational justice and employee satisfaction in \\ performance appraisal. Journal of European Industrial Training. 35. \\ 826-840. Examining the Relationship between Overall Quality, User Satisfaction and Internet Usage: An Integrated Individual, Technological, Organizational and Social Perspective. Asian Journal of Information Technology, 16(1), pp. 100-124.

2. O. Isaac, Z. Abdullah, T. Ramayah, A. M. Mutahar \& I. Alrajawy, (2017). Towards a Better Understanding of Internet Technology Usage by Yemeni Employees in the Public Sector: An Extension of the Task-Technology Fit (TTF) Model. Research Journal of Applied Sciences, 12(2), pp. 205-223.

3. O. Isaac, Z. Abdullah, T. Ramayah, \& A. M. Mutahar, (2017). Internet usage, user satisfaction, task-technology fit, and performance impact among public sector employees in Yemen. The International Journal of Information and Learning Technology, 34(3), pp. 210-241.

4. R. V Krejcie \& D. W. Morgan, (1970). Determining sample size for research activities. Educational and Psychological Measurement, 38, pp. 607-610.

5. V. R. Kannana \& K. C. Tan, (2005). Just in time, total quality management, and supply chain management: understanding their linkages and impact on business performance. Omega: The International Journal of Management Science, 33(2), pp. 153-162.

6. R. B. Kline, (2010). Principles and practice of structural equation modeling (3rd ed.). New York: The Guilford Press.

7. Wolfe, S. E., Rojek, J., Manjarrez, V. M., Jr., \& Rojek, A. (2018). Why does organizational justice matter? Uncertainty management among law enforcement officers. Journal of Criminal Justice, 54, 20-29.

8. Middelkamp-Hup MA, Pathak MA, Parrado C, Goukassian D, Rius-Diaz F, Mihm MC, et al. Oral Polypodium leucotomos extract decreases ultraviolet-induced damage of human skin. J Am Acad Dermatol. 2004; 51, pp. 910-8.

9. M. Abdulrab, A. R. Zumrah, Q. Almaamari, A. N. Al-Tahitah, O. Isaac, \& A. Ameen, (2018). The Role of Psychological Empowerment as a Mediating Variable between Perceived Organizational Support and Organizational Citizenship Behaviour in Malaysian Higher Education Institutions. International Journal of Management and Human Science (IJMHS) Vol. 2. 